\title{
PREPROCESAMIENTO DE DATOS PRELIMINARES PARA CLASIFICADORES EN APRENDIZAJE SUPERVISADO
}

\section{COMPUTER SECURITY IN HIGHER EDUCATION INSTITUTIONS}

Recibido: 24 de septiembre de 2021

Aceptado: 6 de noviembre de 2021
H.R. Lárraga Altamirano ${ }^{1}$

O. Espinosa Guerra ${ }^{2}$ N. Zapata Garay ${ }^{3}$

J. A. Amador Soni ${ }^{4}$

\section{RESUMEN}

Las imágenes obtenidas por percepción remota a través de vehículos aéreos no tripulados proveen de información que incide en la administración del campo y da soporte a la toma de decisiones. El proceso de análisis de estas imágenes involucra diferentes fases, como la adquisición y el preprocesamiento de las mismas. Estos datos son la entrada para métodos de aprendizaje supervisado en la clasificación de imágenes. Ejemplo de estos son las redes neuronales que han marcado un cambio radical en el análisis de información aplicada a la agricultura. Como métodos supervisados de aprendizaje requieren de dos etapas principales para realizar su tarea: el entrenamiento y las pruebas. El desempeño de la red neuronal depende en gran medida de que tan bien se ha conformado las imágenes de entrada que la entrenan para aprender. El presente trabajo propone un método para el preprocesado de imágenes con el objetivo de integrar el conjunto de datos de entrada a una red neuronal artificial (RNA). El método aquí descrito tiene como sujeto de estudio cultivos de caña de azúcar, describe la adquisición de imágenes por medio de vehículos aéreos no tripulados (VANT), su procesamiento para la integración de ortoimágenes, la división en ventanas de menor dimensión y la segmentación de la clase de interés (caña de azúcar).

\section{PALABRAS CLAVE: Preprocesamiento, Segmentación, VANT, Dataset, Entrenamiento}

\section{ABSTRACT}

The images obtained by remote sensing through unmanned aerial vehicles provide information that affects the administration of the field and supports decision-making. The process of analyzing these images involves different phases, such as their acquisition and pre-processing. These data are the input for supervised learning methods in image classification. Example of these are neural networks which have marked a radical change in the analysis of information applied to agriculture. As supervised learning methods they require two main stages to carry out their task: training and tests. The performance of the neural network depends largely on how well it has shaped the input images that train it to learn. The present work proposes a method for the preprocessing of images in order to integrate the input data set to an artificial neural network (ANN). The method described here has as a subject of study sugarcane crops, describes the acquisition of images by means of unmanned aerial vehicles (UAVs), their processing for the integration of orthoimages, the division into smaller windows and the segmentation of the class of interest (sugarcane).

KEY WORDS: Preprocessing, Segmentation, UAV, Dataset, Training

\section{INTRODUCCIÓN}

El campo de la Percepción Remota (PR) ha sido aplicado ampliamente en el estudio de grandes extensiones de tierra a través de información espectral y espacial de la superficie. Para esto, la clasificación de coberturas terrestres es una de las tareas más importantes en el campo de la teledetección, cuyo objetivo es incluir automáticamente etiquetas que definan el

\footnotetext{
${ }^{1}$ Profesor del Tecnológico Nacional de México, Campus Ciudad Valles, hugo.larraga@tecvalles.mx

${ }^{2}$ Profesor del Tecnológico Nacional de México, Campus Ciudad Valles, omar.espinosa@ tecvalles.mx

${ }^{3}$ Profesor del Tecnológico Nacional de México, Campus Ciudad Valles, nitgard.zapata@tecvalles.mx

${ }^{4}$ Estudiante de Maestría del Tecnológico Nacional de México, Campus Ciudad Valles, m20690004@tecvalles.mx
} 
tipo y uso de la tierra física, es decir, el propósito es identificar objetos en una imagen ( $\mathrm{Gu}$, He, \& Yang, 2019).

Las imágenes obtenidas por PR proveen de información que incide en la administración del campo y da soporte a la toma de decisiones. El proceso de análisis de estas imágenes involucra diferentes fases, tales como: Adquisición de imágenes, Digitalización y Compresión, Segmentación, Selección de características, Clasificación e Interpretación (Abdullahi, Sheriff, \& Mahieddine, 2017).

Se han desarrollado varios métodos para la clasificación de imágenes obtenidas por PR en los últimos años dado que la topografía terrestre ha aumentado y se ha mejorado la capacidad de teledetección, hay dos tipos de técnicas: aprendizaje supervisado y aprendizaje no supervisado (Xiaorui, Geng , \& Wang, 2015). Algunas de las técnicas de clasificación de coberturas terrestres son: Distancia Mínima, Máxima verosimilitud, Máquina de vector de soporte, K-NN, Redes Neuronales, entre otras; llamados también clasificadores ( Kulkarni \& Vijaya, 2017).

Las redes neuronales han marcado un cambio radical en el análisis de información aplicada a la agricultura. Como métodos supervisados de aprendizaje requieren de dos etapas principales para realizar su tarea: el entrenamiento y las pruebas. En la etapa de entrenamiento se identifican regiones en las imágenes basándose en los objetos que se desean reconocer para su posterior etiquetado, es decir, se clasifica el conjunto de datos de entrada. El desempeño de la red neuronal depende en gran medida de que tan bien se ha conformado las imágenes de entrada que la entrenan para aprender (Nijhawan, 2017, Junio).

En el presente trabajo estudia las primeras fases del análisis de imágenes mencionadas anteriormente, los cuales comprenden desde la adquisición de las imágenes hasta la segmentación. Estas tareas forman parte del preprocesamiento del conjunto de datos de entrada a una red neuronal artificial (RNA), comprende una serie de operaciones para producir imágenes utilizadas durante el entrenamiento y así mejorar el desempeño de una predicción (Saca, 2018). El método aquí descrito tiene como sujeto de estudio cultivos de caña de azúcar; este describe la adquisición de imágenes por medio de vehículos aéreos no tripulados (VANT), su procesamiento para la integración de ortoimágenes, la división en ventanas de menor dimensión y la segmentación de la clase de interés (caña de azúcar).

\section{METODOLOGÍA}

La estructura general para el desarrollo del sistema se implementa en 2 fases:

\section{Etapa 1. Obtención del conjunto de datos de entrada (Dataset)}

El uso de vehículos aéreos no tripulados (VANT), mejor conocidos como drones, es cada vez más frecuente en tareas de agricultura. La ventaja de volar una superficie a alturas relativamente cortas permite obtener imágenes de alta resolución, las cuales contienen información espectral y espacial de gran utilidad para realizar métricas de la superficie, por ejemplo, de cultivos. Estos vehículos equipados con sensores capaces de medir la radiación solar en diferentes frecuencias, como el espectro infrarrojo (IR) o el infrarrojo cercano (NIR), dan la posibilidad de evaluar la condición en la se encuentra el cultivo. El primer paso para la adquisición de imágenes es realizar un vuelo fotogramétrico sobre las superficies terrestres, para lo cual se cuenta con los siguientes equipos: 
- DJI Phantom 4 Pro

- Cámara multiespectral Parrot Sequoia

Los sujetos de estudio corresponden a 3 cultivos de caña de azúcar ubicados en las cercanías de la cabecera municipal de Ciudad Valles, acumulando un área promedio de 20 hectáreas. La fotogrametría de los cultivos intenta realizarse en RGB (bandas rojo, verde y azul), el horario propuesto para los vuelos es de 8 a 10 am, considerando que las condiciones climáticas sean las mismas para cada caso (Ghazal, 2019).

El VANT almacena la galería de imágenes que se requiere para el siguiente paso, la integración del ortomosaico ("mapa" del cultivo). El proceso de construcción de mapas se realiza con software de proceso o de transformación conocido como Pix4D Mapper. Este software posee robustas capacidades para convertir las imágenes RGB en productos cartográficos como: el mapa de reflectancia, el modelo de elevaciones, nube de puntos, entre otros (Treboux, 2018, Junio).

\section{Etapa 2. Preprocesamiento}

El preprocesamiento de estas galerías consiste en producir una basta cantidad de imágenes que sirva de entrenamiento al método de clasificación propuesto (una red neuronal convolucional). Existe en la literatura una variedad de propuestas interesantes para poder seleccionar las características que identifiquen inequívocamente al cultivo de caña de azúcar, algunos son: K-nearest neighbour (KNN) y Support Vector Machine (SVM) (Xiao Lei \& Peng, 2020). Sin embargo, para este estudio se realizarán dos operaciones básicamente:

- Recorte: Las dimensiones de la ortoimagen del cultivo son muy grandes para considerarse como entrada de algún método supervisado de aprendizaje, por lo tanto, la ortoimagen original se divide en subimágenes con una dimensión menor, 256px x 256px. De estas imágenes se seleccionan aquellas que contengan cultivos de caña de azúcar abarcando la mayor parte de la fotografía. De la misma manera se seleccionan las clases de suelo y otra vegetación (Castillo \& Díaz, 2015).

- Segmentación: Las redes neuronales son métodos de aprendizaje supervisado, por lo tanto, requieren de datos etiquetados para su entrenamiento. Las imágenes solo deben de contener aquella área que muestre el cultivo de la caña de azúcar, es por eso que, se extrae la región de interés (ROI) mediante métodos de segmentación basados en umbralización (Jia, 2019).

\section{RESULTADOS}

\section{El dataset}

Los vuelos fotogramétricos se realizaron con ayuda del software Pix4D Capture, de distribución gratuita disponible para plataformas Android y iOS. Los parámetros a tomar en cuenta para el vuelo autónomo son la altura (50-70 metros), velocidad del VANT (media), ángulo de la cámara (90 grados), empalme (85\%), dirección (frente). La misión de tipo reja es usada para mapeo en 2D, como se muestra en la Figura 1. 


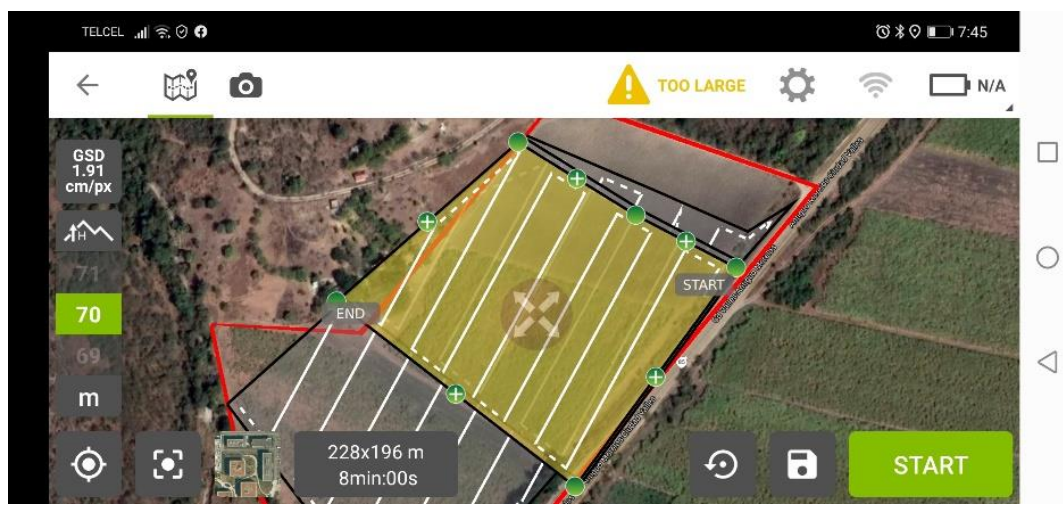

Figura 1. Planeación del vuelo autónomo. Fuente Pix4D Capture

Las imágenes capturadas en cada vuelo conforman una galería de 648 fotografías en el espacio de color RGB con una resolución de 4608px x 3456px. La generación de las ortoimágenes de los cultivos de caña de azúcar se realizó en el programa de procesamiento Pix4D Mapper. El parámetro empalme con un ajuste al $85 \%$ es de suma importancia para traslapar sin pérdida de datos las imágenes y así integrarlas en un ortomosaico, la Figura 2 presenta el resultado final del procesamiento.
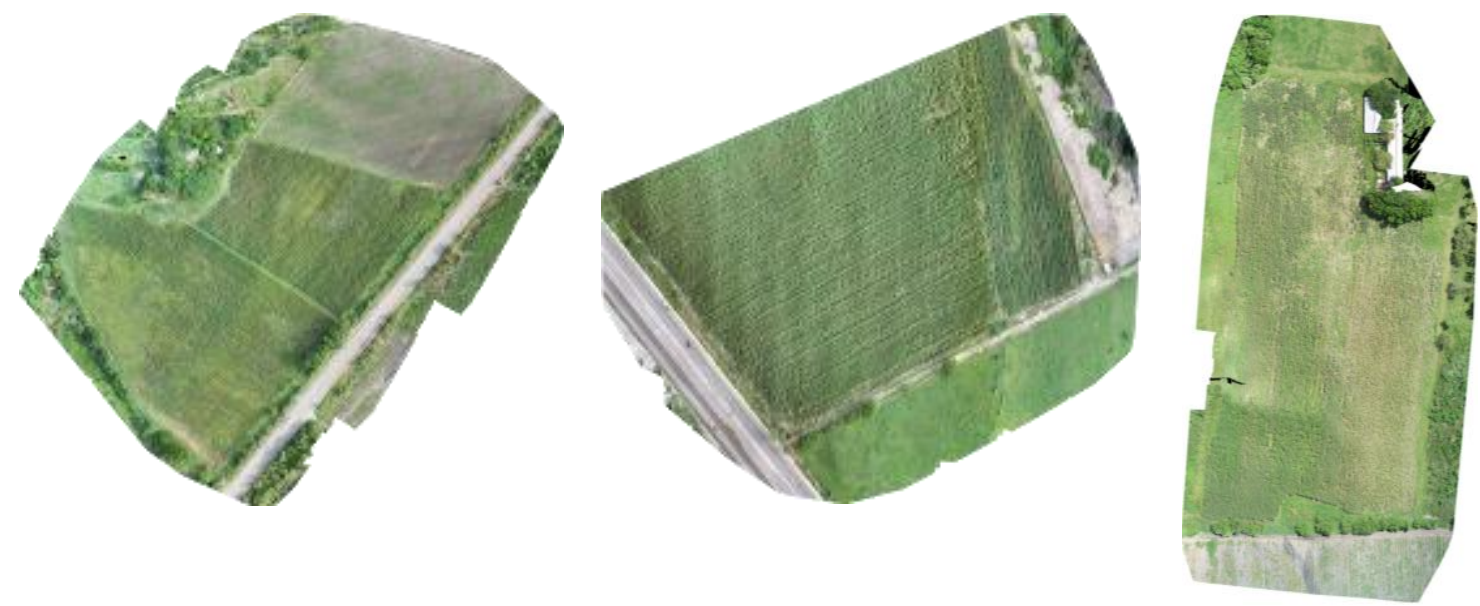

Figura 2. Ortoimágenes de las 3 parcelas estudiadas. Fuente Pix4D Mapper

\section{Recorte}

Los "mapas" de los cultivos son imágenes sumamente grandes en dimensiones, tomando como referencia el orden de la figura anterior el tamaño de las ortoimágenes es de $9648 \mathrm{x}$ $8745 ; 12034$ x 7365 en los dos últimos casos, la unidad de medida son pixeles. El aprendizaje supervisado en la fase de entrenamiento requiere de entradas que no saturen al clasificador por la cantidad de parámetros que se generan durante el proceso. Por lo tanto, se diseñó un programa en Python 3.8.8 mediante las herramientas de la plataforma Anaconda y la herramienta Jupyter NoteBook.

La idea general del recorte, es extraer subimágenes de dimensiones de 256px x 256px. El algoritmo funciona como una ventana que se desliza del margen izquierdo de la ortoimagen hasta el límite derecho, iniciando en la parte superior de la misma y terminando hasta el límite inferior, ver Figura 3. 


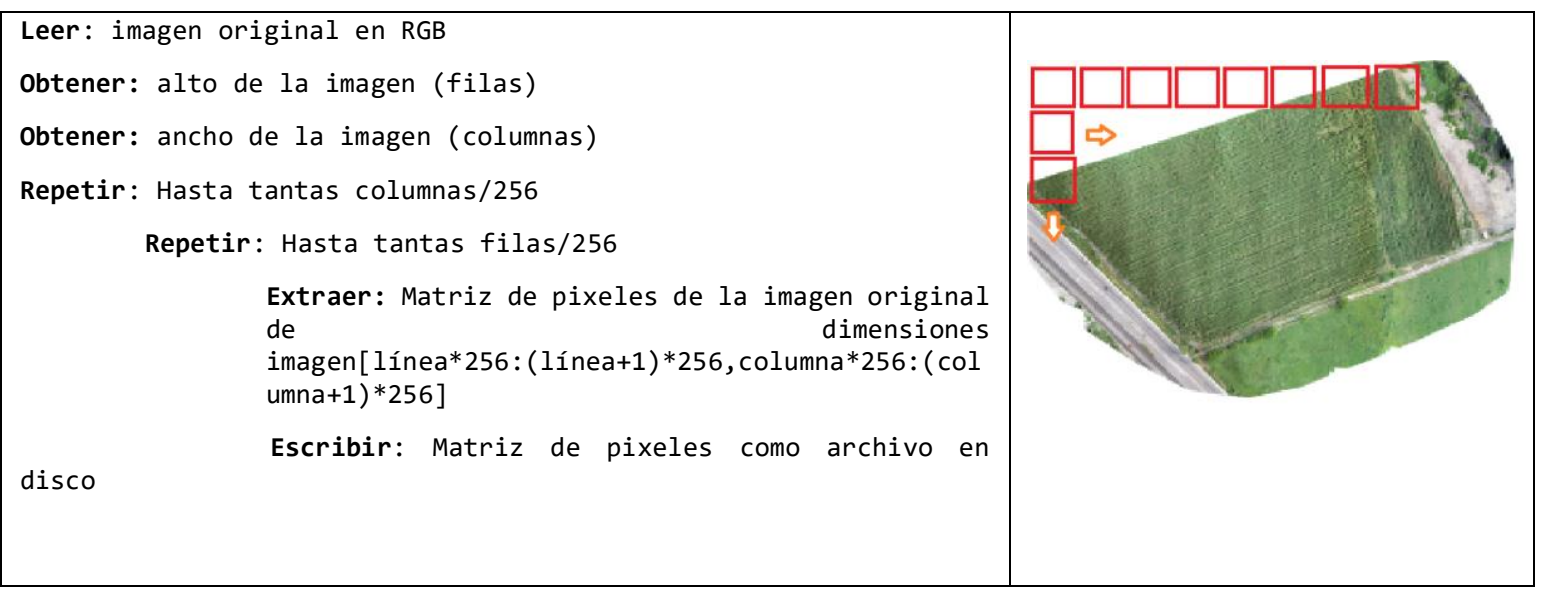

Figura 3. Algoritmo de recorte. Fuente original

Las subimágenes fueron clasificadas considerando cuatro clases diferentes: caña, suelo, otra vegetación y desechables, imágenes que no aportan suficiente información de las clases, se concentran en los márgenes de la ortofoto, la Tabla 1 describe el conjunto de datos completo.

Tabla 1. Conjunto de datos completo. Fuente original

\begin{tabular}{|l|l|l|l|l|l|}
\hline Predio & $\begin{array}{l}\text { Imágenes } \\
\text { recortadas }\end{array}$ & Clase Caña & Clase Suelo & $\begin{array}{l}\text { Clase Otra } \\
\text { Vegetación }\end{array}$ & $\begin{array}{l}\text { Clase } \\
\text { Desechables }\end{array}$ \\
\hline Cultivo 1 & 1258 & 324 & 188 & 219 & 527 \\
\hline Cultivo 2 & 1316 & 538 & 138 & 252 & 388 \\
\hline Cultivo 3 & 2655 & 521 & 632 & 704 & 798 \\
\hline Totales & 5229 & 1383 & 958 & 1175 & 1713 \\
\hline
\end{tabular}

\section{Segmentación}

El proceso de segmentación extrae solo los objetos de interés de una imagen, en este caso, los pixeles que definen la caña de azúcar. Esta tarea genera nuevos datos de entrada, sin el ruido que generan los pixeles no representativos de cada clase. La técnica de segmentación seleccionada fue la umbralización, este, establece un umbral T (valor de intensidad) y usa T para dividir los datos de la imagen en dos grupos: pixeles mayores que $\mathrm{T}$ y píxeles más pequeños que T. Este método fue seleccionado debido a la escala de grises del objetivo y el fondo de la imagen que presentan un fuerte contraste. La programación del método se realizó en Python con el API OpenCV.

Se determinó el umbral mediante el análisis de los histogramas en imágenes muestra convertidas de un espacio de color RGB a escala de grises, como se ve en la Figura 4. 

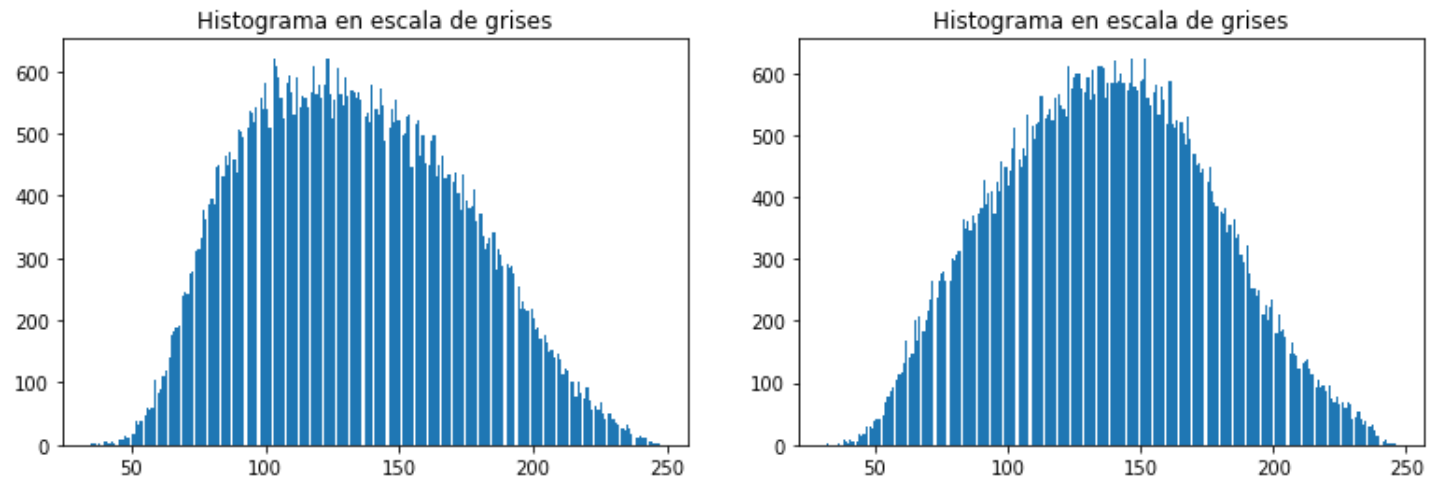

Figura 4. Histogramas de imágenes muestra. Fuente original

Los umbrales identificados por la función Treshold oscilan entre los valores de intensidad 134 y 137. Los histogramas muestran una curvatura normal confirmando el alto contraste entre la clase y el resto de la imagen. La binarización de la imagen se logró con la implementación del operador Otsu, el cual calcula un umbral local para discriminar con mayor eficacia los pixeles de interés de los que no lo son. Los resultados de este proceso se observan en la Figura 5.

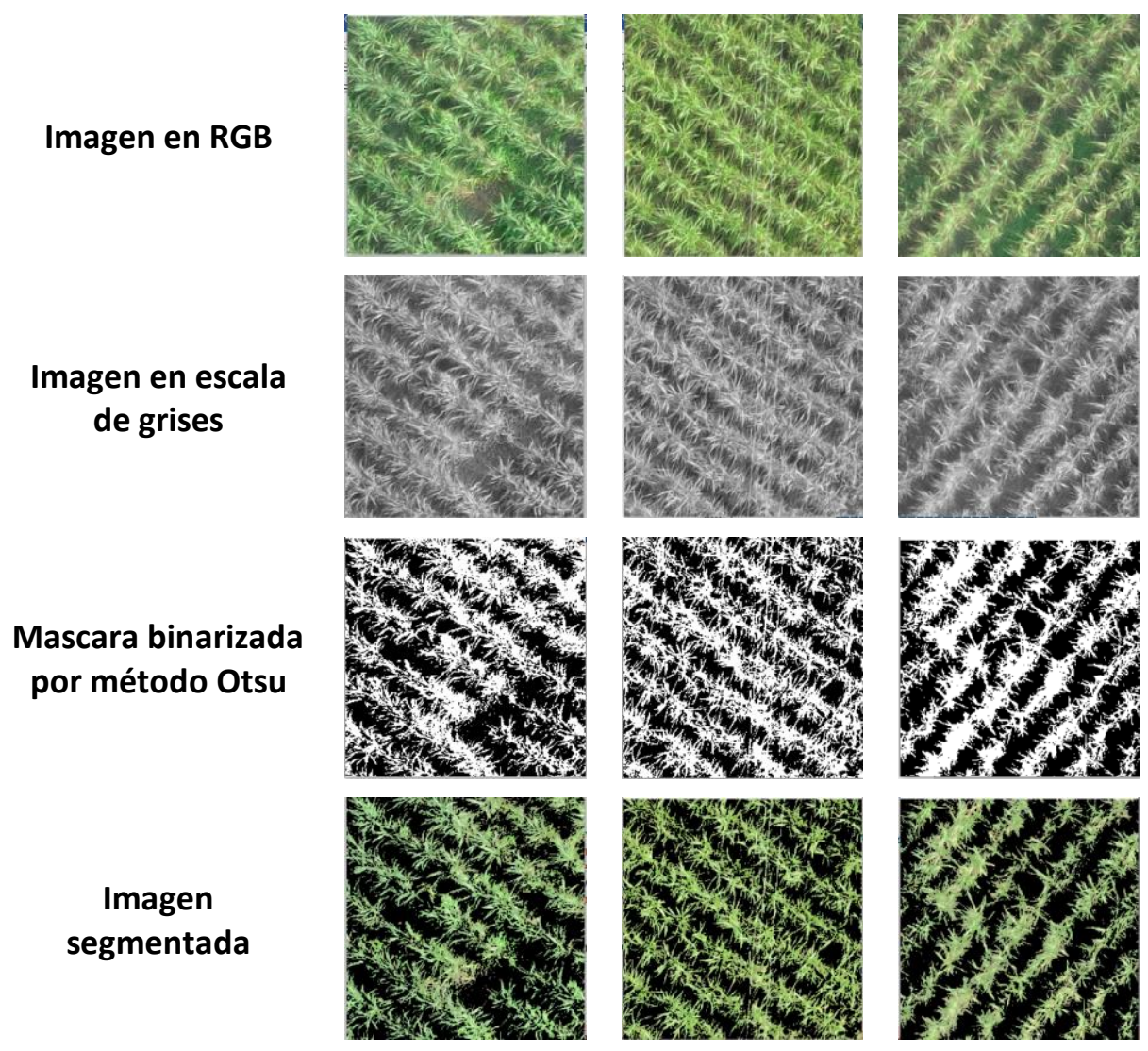

Figura 5. Resultados del preprocesamiento. Fuente original 
La imagen segmentada es una multiplicación pixel por pixel de la máscara binarizada y la imagen original, el operador bitwise_and permitió este producto dando como resultado, la segmentación.

\section{Discusión}

Trabajar con OpenCV y Python permitió que las imágenes sean tratadas como matrices de valores por lo que las operaciones sobre estas fueron relativamente fáciles de implementar, tal es el caso de la transformación del espacio de color RGB a escala de grises, o bien, el producto pixel por pixel de la imagen original y la máscara. El tamaño de la ventana móvil 256px x 256px puede variar en caso de que se requieran entradas de otras dimensiones, con lo cual el preprocesamiento no tendría cambios sustantivos. Aunque existen diferentes técnicas de segmentación, la umbralización por Otsu es computacionalmente poco costosa, y para este caso en el que el contraste de la caña y el resto de la imagen es alto, fue efectivo.

\section{CONCLUSIONES}

El preprocesamiento de las imágenes de cultivos de caña de azúcar atiende la fase de entrenamiento de un clasificador, proveyendo de un conjunto de datos de entrada con clases bien definidas por el conjunto de pixeles que en realidad las representan. Durante el proceso de adquisición de imágenes con los VANT, se observó que el parámetro de empalme (overlapping) es crucial para la integración del ortomosaico, se recomienda usar como valor mínimo el $85 \%$ para obtener productos 2D de buena calidad.

La finalidad de este tipo de aplicaciones es que sean una herramienta para construir el conjunto de datos de entrada que serán procesados por una red neuronal entrenada para aprender a clasificar los cultivos de caña de azúcar. La clasificación de coberturas terrestres como los cultivos, da más información a los administradores del campo para tomar decisiones basadas en sostenibilidad y sustentabilidad.

\section{BIBLIOGRAFÍA}

Kulkarni, K., \& Vijaya, P. (2017). A comparitive study of land classification using remotely sensed data. IEEE, 6 .

Abdullahi, H. S., Sheriff, R. E., \& Mahieddine, F. (2017). Convolution neural network in precision agriculture for plant image recognition and classification. Seventh International Conference on Innovative Computing Technology (Intech) (págs. 1-3). Londrés: IEEE.

Castillo, J. Z., \& Díaz, R. L. (2015). Desarrollo e implementación de un sistema aéreo de conteo en plantaciones de palma de aceite. Bucaramanga: Universidad Pontificia Bolivariana.

Ghazal, M. (2019). Vegetation Cover Estimation Using Convolutional Neural Networks. IEEE, 18.

Gu, L., He, F., \& Yang, S. (2019). Crop Classification Based on Deep Learning in. 4.

Jia, M. L. (2019). A newly developed method to extract the optimal hyperspectral feature for monitoring leaf biomass in wheat. Computers and Electronics in Agriculture, 145. 
Nijhawan, R. S. (2017, Junio). Land cover classification using super-vised and unsupervised learning techniques. In 2017 International Conference on Computational Intelligence in Data Science (ICCIDS) (págs. 1-6). IEEE.

Saca, F. L. (2018). Preprocesamiento de bases de datos de imágenes para mejorar el rendimiento de redes neuronales convolucionales. Research in Computing Science, 147, 35-45.

Treboux, J. \&. (2018, Junio). Improved machine learning methodology for high precision agriculture. In 2018 Global Internet of Things Summit (GIoTS) (págs. 1-6). IEEE.

Xiaorui, M., Geng, J., \& Wang, H. (2015). Hyperspectral image classification via. Springer, 12 . 